\title{
SIKAP PETANI PLASMA KELAPA SAWIT \\ TERHADAP KINERJA PELAYANAN DAN KEGIATAN \\ KOPERASI UNIT DESA (KUD) KARYA TANI \\ DI DESA PANDU SANJAYA KECAMATAN PANGKALAN LADA KABUPATEN KOTAWARINGIN BARAT
}

\author{
ATTITUDE OF PALM OIL PLASMA FARMERS \\ THE PERFORMANCE SERVICE AND ACTIVITIES \\ AT VILLAGE UNIT COOPERATIVE (KUD) KARYA TANI \\ IN PANDU SANJAYA VILLAGE, PANGKALAN LADA SUBDISTRICT, \\ KOTAWARINGIN BARAT DISTRICT \\ ${ }^{1}$ Yulianti, ${ }^{2}$ Masliani, ${ }^{3}$ H. Ahmad Zaki Yamani \\ ${ }^{1}$ Alumnus Program Studi Agribisnis, Fakultas Pertanian, Universitas Palangka Raya \\ ${ }^{2,3}$ Staf Pengajar Program Studi Agribisnis, Fakultas Pertanian, Universitas Palangka Raya \\ email:maslianijailani@agb.upr.ac.id
}

\begin{abstract}
ABSTRAK
Sikap petani plasma kelapa sawit terhadap kinerja pelayanan dan kegiatan pada KUD Karya Tani di Desa Pandu Sanjaya, Kecamatan Pangkalan Lada, Kabupaten Kotawaringin Barat termasuk dalam kriteria baik. Sikap ini dipengaruhi oleh 4 indikator variabel antara lain: 1). Sikap petani plasma kelapa sawit terhadap kinerja pelayanan pinjaman; 2). Penilaian sikap petani plasma kelapa sawit terhadap kinerja pelayanan penyediaan pupuk; 3). Penilaian sikap petani plasma kelapa sawit terhadap kinerja pelayanan pembagian SHU; 4). Penilaian sikap petani plasma kelapa sawit terhadap kegiatan kinerja Rapat Anggota Tahunan (RAT) dan iuran tahunan. Dengan demikian, penilaian sikap petani plasma kelapa sawit terhadap pelayanan dan kegiatan Koperasi Unit Desa (KUD) Karya Tani di Desa Pandu Sanjaya, Kecamatan Pangkalan Lada, Kabupaten Kotawaringin Barat termasuk dalam keriteria "Baik". Sementara permasalahan yang dihadapi oleh petani plasma kelapa sawit terhadap kinerja pelayanan dan kegiatan KUD Karya Tani di Desa Pandu Sanjaya yaitu masalah dalam keterbatasan penyediaan pupuk, terbatasnya stok pupuk yang ada di KUD Karya Tani membuat anggota petani plasma harus mencarinya di luar untuk memenuhi jumlah pupuk yang diperlukan. Masalah lain yang dihadapi oleh KUD Karya Tani yaitu masalah dalam hal pelayanan, KUD Karya Tani membatasi pinjaman untuk anggota plasma sebesar Rp 30.000.000,-. Hal ini berdampak pada petani plasma kelapa sawit dalam memenuhi keperluannya.
\end{abstract}

Kata Kunci: Kelapa sawit, kinerja pelayanan, KUD Karya Tani, Pandu Sanjaya, sikap petani

\section{ABSTRACT}

The attitude of oil palm plasma farmers towards the performance of services and activities at KUD Karya Tani in Pandu Sanjaya Village, Pangkalan Lada Subdistrict, West Kotawaringin District is included in good criteria. This attitude is influenced by 4 indicator variables including: 1). Attitudes of oil palm smallholder farmers towards loan service performance; 2). Assessment of palm oil plasma farmers' attitudes toward fertilizer supply service 
performance; 3). Assessment of palm oil plasma farmers' attitudes toward SHU distribution service performance; 4). Evaluation of palm oil plasma farmers' attitudes toward Annual Members Meeting (RAT) and annual fee activities. Thus the attitude of oil palm smallholder farmers' attitudes to the services and activities of KUD Karya Tani in Pandu Sanjaya Village, Pangkalan Lada Subdistrict, West Kotawaringin District is included in the "Good" criteria. While the problems faced by palm oil plasma farmers on the performance of KUD Karya Tani's activities in Pandu Sanjaya Village are problems in the limited supply of fertilizers, the limited fertilizer stock in KUD Karya Tani makes members of plasma farmers have to look for them outside to meet the amount of fertilizer needed. Another problem faced by KUD Karya Tani is a problem in terms of service, KUD Karya Tani limits loans to plasma members of Rp 30,000,000, - this has an impact on smallholders of palm oil to meet their needs.

Keywords: Farmers attitude, KUD Karya Tani, oil palm, Pandu Sanjaya, service performance

\section{PENDAHULUAN}

\section{Latar Belakang}

Pembangunan pertanian merupakan suatu kegiatan yang dilakukan pada sektor pertanian yang bertujuan untuk meningkatkan kesejahteraan dan meningkatkan kualitas hidup petani yang lebih baik. Permasalahan baru pada pembangunan pertanian adalah menempatkan para petani sebagai subjek tidak lagi menjadi objek dalam kegiatan pembangunan pertanian, sebagai programprogram dalam kegiatan pembangunan akan lebih bersifat bottom-up (berdasarkan kebutuhan para petani sendiri dan pemerintah hanya sebagai fasilitator). Pembangunan adalah suatu proses multidimensi dengan melibatkan perubahan yang besar dalam struktur sosial, sikap mental, kelembagaan nasional, termasuk akselerasi pertumbuhan ekonomi, pemerataan pembangunan, pengurangan pengangguran, dan pengurangan kemiskinan (Zakaria, 2008).

Provinsi Kalimantan Tengah melakukan pengembangan pembangunan perkebunan kelapa sawit yang dapat meningkatkan tingkat perekonomian masyarakat dan dapat menyerap tenaga kerja. Dengan adanya penyerapan tenaga kerja di sektor perkebunan kelapa sawit diharapkan dapat mengurangi tingkat pengangguran yang ada di Kalimantan Tengah. Berdasarkan luas areal perkebunan kelapa sawit rakyat menurut kecamatan di Kabupaten Kotawaringin Barat memiliki luas 36.021,95 Ha dengan produksi buah kelapa sawit sebanyak 68.212,87 Ton. Kecamatan Pangkalan Lada merupakan daerah yang menempati posisi pertama tertinggi di Kabupaten Kotawaringin Barat dengan luas areal 11.805,00 Ha dengan produksi kelapa sawit sebesar 27.028,72 Ton. Untuk wilayah Kecamatan Pangkalan Lada merupakan salah satu kecamatan yang berada di daerah Kabupaten Kotawaringin Barat dengan Luas wilayah sebesar 229 $\mathrm{Km}^{2}$ atau 3,08\% dari total luas Kabupaten Kotawaringin Barat (Badan Pusat Statistik Provinsi Kalimantan Tengah, 2018).

Kecamatan Pangkalan Lada terdiri dari 11 Desa, 26 Dusun, 51 RW dan 206 RT. Awalnya desa-desa di Kecamatan Pangkalan Lada merupakan desa transmigran yang masuk di Kabupaten Kotawaringin Barat sejak tahun 1970. Untuk Desa Pandu Sanjaya sendiri merupakan salah satu desa dan merupakan ibu kota Kecamatan Pangkalan Lada. Sedangkan perkebunan rakyat kelapa sawit di daerah Kecamatan Pangkalan Lada memiliki luas $11.805,00 \mathrm{Ha}$ pada tahun 2017. Berdasarkan data di atas, Desa Pandu Sanjaya menempati urutan pertama 
dalam perkebunan kelapa sawit terbesar dengan luas areal mencapai 2.650,00 Ha, sedangkan untuk desa dengan luas perkebunan kelapa sawit terkecil terdapat pada Desa Pangkalan Durin dengan luas 65,00 Ha (Badan Pusat Statistik Kabupaten Kotawaringin Barat, 2018).

$$
\text { Sejalan dengan tujuan }
$$

pembangunan pertanian yang membangun sistem agribisnis yang berkesinambungan antar sektor dan wilayah, dengan ini sangat diperlukan lembaga pertanian yang berfungsi untuk mengembangkan komoditas serta sistem pelayanan bagi para petani baik dalam teknik budidaya, penyediaan kredit usaha, dan penyuluhan pertanian dengan harapan dapat meningkatkan komoditas dijaman pasar bebas. Demikian pembangunan pertanian sistem agibisnis dalam perkebunan rakyat kelapa sawit di Kecamatan Pangkalan Lada perlu mengutamakan pada pembangunan kelembagaan petani.

$\begin{array}{llr}\text { Koperasi Unit Desa } & \text { (KUD) } \\ \text { merupakan badan } & \text { usaha } & \text { yang }\end{array}$
beranggotakan orang atau badan hukum yang berlandaskan pada asas kekeluargaan dan demokrasi ekonomi. KUD berfungsi dalam kegiatan pelayanan kepada masyarakat, antara lain kepada para petani plasma kelapa sawit sebagai anggotanya seta masyarakat umum yang disekitarnya. Kegiatan-kegiatan pelayanan KUD berupa perkreditan, simpan pinjam, pemasaran, pengangkutan dan usaha jasa lainnya. Terletak di Desa Pandu Sanjaya terdapat KUD Karya Tani yang memiliki jumlah anggota terbanyak yaitu mencapai 1.266 orang. Koperasi Unit Desa (KUD) Karya Tani sendiri terbentuk pada tahun 1984 dengan jumlah anggota sebanyak 57 orang dan memiliki Badan Hukum Nomor: 883/BH/XIX, Tanggal 20 Juli 1985 hingga akhir tahun 2018 jumlah anggota KUD Karya Tani sudah mencapai 1.266 orang (Dinas Koperasi dan UKM Provinsi Kalimantan Tengah, 2018).

Berdasarkan dari permasalahan di atas, maka tujuan penelitian ini adalah mengetahui sikap dan permasalahan petani plasma terhadap kinerja pelayanan dan kegiatan KUD Karya Tani di Desa Pandu Sanjaya, Kecamatan Pangkalan Lada, Kabupaten Kotawaringin Barat.

\section{METODE PENELITIAN}

Penelitian ini menggunakan metode survei. Penentuan lokasi penelitian secara sengaja (purposive) yaitu di KUD Karya Tani Desa Pandu Sanjaya, Kecamatan Pangkalan Lada, Kabupaten Kotawaringin Barat. Pengambilan sampel responden dilakukan terhadap populasi petani yang tergabung sebagai anggota KUD Karya Tani di Desa Pandu Sanjaya yang memiliki area lahan plasma kelapa sawit seluas $1.030 \mathrm{Ha}$ dengan jumlah anggota KUD Karya Tani sebanyak 1.266 orang, Jumlah sampel ditentukan dengan menggunakan perhitungan rumus Slovin dengan tingkat kesalahan 15\% (Arikunto, 2010), sehingga jumlah sampel yang diambil sebanyak 43 responden.

Untuk menjawab tujuan pertama mengetahui sikap petani plasma terhadap pelayanan dan kegiatan KUD Karya Tani di Desa Pandu Sanjaya, Kecamatan Pangkalan Lada, menggunakan analisis kualitatif dengan menggunakan metode scoring skala Likert (Sugiyono, 2017). Kemudian untuk menjawab tujuan kedua, yaitu mengetahui permasalahan yang dihadapi petani plasma terhadap pelayanan KUD Karya Tani di Desa Pandu Sanjaya, Kecamatan Pangkalan Lada, Kabupaten Kotawaringin Barat menggunakan analisis deskriptif.

\section{HASIL DAN PEMBAHASAN}

Sikap petani plasma kelapa sawit terhadap pelayanan dan kegiatan KUD Karya Tani di Desa Pandu Sanjaya terdiri dari: sikap petani plasma kelapa sawit terhadap pelayanan pinjaman pada KUD Karya Tani di Desa Pandu Sanjaya, Kecamatan Pangkalan Lada, sikap petani 
plasma kelapa sawit terhadap pelayanan penyediaan pupuk pada KUD Karya Tani di Desa Pandu Sanjaya, Kecamatan Pangkalan Lada, sikap petani plasma kelapa sawit terhadap pelayanan pemberiaan SHU pada KUD Karya Tani di Desa Pandu Senjaya, Kecamatan Pangkalan Lada, sikap petani plasma kelapa sawit terhadap kegiatan RAT dan iuran pada KUD Karya Tani di Desa Pandu Senjaya, Kecamatan Pangkalan Lada, serta permasalahan yang dihadapi petani plasma kelapa sawit terhadap pelayanan pnijaman pada KUD Karya Tani di Desa Pandu Sanjaya, Kecamatan Pangkalan Lada.

\section{Sikap Petani Plasma Kelapa Sawit Terhadap Kinerja Pelayanan Pinjaman pada KUD Karya Tani di Desa Pandu Sanjaya, Kecamatan Pangkalan Lada}

Agar dapat mengetahui sikap petani plasma kelapa sawit terhadap kinerja pelayanan pinjaman KUD Karya Tani di Desa Pandu Sanjaya, Kecamatan Pangkalan Lada yaitu menggunakan kuesioner dengan 10 pertanyaan yang ditanyakan kepada responden yang bermukim di Desa Pandu Sanjaya, Kecamatan Pangkalan Lada. Adapun Tabel 1 menunjukkan sikap petani plasma kelapa sawit terhadap kinerja pelayanan pinjaman pada KUD Karya Tani di Desa Pandu Sanjaya, Kecamatan Pangkalan Lada.

Tabel 1. Penilaian Sikap Petani Plasma Kelapa Sawit Terhadap Kinerja Pelayanan Pinjaman Pada KUD Karya Tani di Desa Pandu Sanjaya Kecamatan Pangkalan Lada

\begin{tabular}{|c|c|c|c|c|}
\hline \multirow[b]{2}{*}{ No. } & \multirow[b]{2}{*}{ Pernyataan } & \multicolumn{2}{|c|}{ Analisis Skoring } & \multirow[b]{2}{*}{ Kriteria } \\
\hline & & $\begin{array}{l}\text { Jumlah } \\
\text { Skoring }\end{array}$ & $\begin{array}{c}\text { Indeks } \\
(\%)\end{array}$ & \\
\hline 1 & Proses pinjaman dana dari KUD mudah dan cepat & 174 & 8,09 & \\
\hline 2 & Besar pinjaman ditentukan oleh anggota KUD & 143 & 6,65 & \\
\hline 3 & $\begin{array}{l}\text { Jika terlambat membayar angsuran, maka } \\
\text { peminjam dikenai denda }\end{array}$ & 169 & 7,86 & \\
\hline 4 & $\begin{array}{l}\text { Batas waktu lamanya mengangsur ditentukan } \\
\text { bersama-sama antara peminjam KUD }\end{array}$ & 170 & 7,91 & \\
\hline 5 & $\begin{array}{l}\text { Anggota bisa melakukan peminjaman kapan saja } \\
\text { disaat membutuhkan dana }\end{array}$ & 166 & 7,72 & \\
\hline 6 & Pinjaman dari KUD ada bunga dan jaminan & 172 & 8,00 & \\
\hline 7 & $\begin{array}{l}\text { Jika terlambat membayar angsuran, maka } \\
\text { peminjam dikenai denda }\end{array}$ & 140 & 6,51 & \\
\hline 8 & $\begin{array}{l}\text { Besaran denda yang harus dibayar tidak } \\
\text { memberatkan anggota sebagai peminjam }\end{array}$ & 155 & 7,20 & \\
\hline 9 & $\begin{array}{l}\text { Ada syarat khusus untuk anggota yang ingin } \\
\text { meminjam dana KUD }\end{array}$ & 157 & 7,30 & \\
\hline 10 & $\begin{array}{l}\text { Pinjaman yang diberikan untuk anggota KUD } \\
\text { berupa uang tunai }\end{array}$ & 117 & 5,44 & \\
\hline & Total & 1,563 & 72,68 & Baik \\
\hline
\end{tabular}

Sumber: Data Primer yang Diolah, 2019.

Berdasarkan hasil penelitian yang disajikan pada Tabel 1, menunjukkan bahwa sikap petani plasma kelapa sawit terhadap kinerja pelayanan pinjaman pada
KUD Karya Tani di Desa Pandu Sanjaya, Kecamatan Pangkalan Lada memiliki total skor sebanyak $1,563(72,68 \%)$, dimana termasuk dalam kriteria "Baik". 
Berdasarkan dari wawancara seluruh anggota plasma kelapa sawit menunjukkan bahwa petani plasma kelapa sawit merasa puas dan menikmati pelayanan yang diberikan oleh KUD Karya Tani khususnya pada pelayanan simpan pinjaman. Hasil penelitian sampai saat ini program simpan pinjam sudah terealisasi dan anggota petani plasma merasakan dampak yang baik dengan adanya pelayanan simpan pinjaman karena KUD Karya Tani tidak hanya memberikan pinjaman dalam bentuk uang saja melainkan memberikan bantuan pinjaman dalam bentuk lain seperti kredit motor dan furniture. Untuk jumlah uang yang dipinjamkan KUD Karya Tani memberikan batas waktu lamanya untuk mengangsur dan ditentukan bersama dengan anggota unit simpan pinjam dengan petani plasma. Namun ada beberapa anggota petani plasma merasa bahwa ada sedikit permasalahan dalam hal pinjaman modal, anggota petani plasma berharap bahwa KUD Karya Tani bisa memberikan pinjaman modal sesuai dengan kebutuhan anggota petani plasma tanpa adanya batasan pinjaman.

\section{Sikap Petani Plasma Kelapa Sawit Terhadap Kinerja Pelayanan Penyediaan Pupuk pada KUD Karya Tani di Desa Pandu Sanjaya, Kecamatan Pangkalan Lada}

Untuk mengetahui sikap petani plasma kelapa sawit terhadap kinerja pelayanan penyediaan pupuk KUD Karya Tani di Desa Pandu Sanjaya, Kecamatan Pangkalan Lada yaitu menggunakan kuesioner yang berisikan 6 pertanyaan yang disajikan kepada 43 responden yang bermukim di Desa Pandu Sanjaya, Kecamatan Pangkalan Lada. Adapun Tabel 2. menyajikan sikap petani plasma kelapa sawit terhadap kinerja pelayanan penyediaan pupuk pada KUD Karya Tani di Desa Pandu Sanjaya, Kecamatan Pangkalan Lada.

Tabel 2. Penilaian Sikap Petani Plasma Kelapa Sawit Terhadap Kinerja Pelayanan Penyediaan Pupuk Pada KUD Karya Tani di Desa Pandu Sanjaya Kecamatan Pangkalan Lada

\begin{tabular}{|c|c|c|c|c|}
\hline \multirow[b]{2}{*}{ No. } & \multirow[b]{2}{*}{ Pernyataan } & \multicolumn{2}{|c|}{ Analisis Skoring } & \multirow[b]{2}{*}{ Kriteria } \\
\hline & & $\begin{array}{l}\text { Jumlah } \\
\text { Skoring }\end{array}$ & $\begin{array}{c}\text { Indeks } \\
(\%)\end{array}$ & \\
\hline 1. & $\begin{array}{l}\text { KUD menyediakan pupuk dan menjualnya khusus } \\
\text { untuk anggota KUD }\end{array}$ & 181 & 14,03 & \\
\hline 2. & $\begin{array}{l}\text { Jam pelayanan KUD sesuai dengan jam kerja pada } \\
\text { umumnya }\end{array}$ & 169 & 10,00 & \\
\hline 3. & $\begin{array}{l}\text { Jenis pupuk yang disediakan KUD sesuai dengan } \\
\text { kebutuhan lahan plasma kelapa sawit }\end{array}$ & 180 & 13,95 & \\
\hline 4. & $\begin{array}{l}\text { Harga yang diberikan pihak KUD sudah sesuai } \\
\text { dengan harga ditempat lain }\end{array}$ & 175 & 13,56 & \\
\hline 5. & $\begin{array}{l}\text { Jumlah pupuk yang diminta petani plasma sudah } \\
\text { sesuai dengan permintaan }\end{array}$ & 176 & 13,64 & \\
\hline 6. & $\begin{array}{l}\text { Kualitas pupuk yang diberikan KUD sudah baik, } \\
\text { bersegel dan berlabel }\end{array}$ & 179 & 13,87 & \\
\hline & Total & 1.060 & 79,05 & Baik \\
\hline
\end{tabular}

Sumber: Data Primer yang Diolah, 2019.

Berdasarkan Tabel 2, diketahui bahwa sikap petani plasma kelapa sawit terhadap kinerja pelayanan penyediaan pupuk pada KUD Karya Tani di Desa
Pandu Sanjaya, Kecamatan Pangkalan Lada memiliki total skor sebesar 1.060 $(79,05 \%)$, artinya berkriteria "Baik". Ketersediaan pupuk bersubsidi yang ada di 
KUD Karya Tani dapat mencukupi kebutuhan petani plasma kelapa sawit serta jam pelayanan yang sesuai dengan jam kerja yang sudah ditentukan dan kondisi pupuk baik, bersegel dan berlabel. Namun ada sedikit permasalahan yang dirasakan oleh beberapa anggota petani plasma yang seharusnya KUD Karya Tani menyediakan berbagai macam jenis pupuk pertanian seperti Dolomit, SP-36, dan Borak supaya petani plasma kelapa sawit di Desa Pandu Sanjaya lebih terbantu dalam mendapatkan jenis-jenis pupuk pertanian yang akan digunakannya. Sedangkan jenis pupuk yang ada pada KUD Karya tani yaitu jenis pupuk Urea, KCL, TSP, dan NPK dengan harga yang sedikit miring dibanding harga di pasaran.

\section{Sikap Petani Plasma Kelapa Sawit Terhadap Kinerja Pelayanan Pembagian SHU pada KUD Karya Tani di Desa Pandu Sanjaya, Kecamatan Pangkalan Lada}

Untuk mengetahui sikap petani plasma kelapa sawit terhadap kinerja pelayanan pembagian SHU pada KUD Karya Tani di Desa Pandu Sanjaya, Kecamatan Pangkalan Lada yaitu menggunakan kuesioner yang berisikan 10 pertanyaan yang akan diberikan kepada 43 responden petani plasma kelapa sawit yang bermukim di Desa Pandu Sanjaya Kecamatan Pangkalan Lada. Untuk lebih jelasnya sikap petani plasma kelapa sawit terhadap kinerja pelayanan pembagian SHU pada KUD Karya Tani di Desa Pandu Sanjaya, Kecamatan Pangkalan Lada dapat dilihat seperti pada Tabel 3 berikut.

Tabel 3. Penilaian Sikap Petani Plasma Kelapa Sawit Terhadap Kinerja Pelayanan Pembagian SHU pada KUD Karya Tani di Desa Pandu Sanjaya Kecamatan Pangkalan Lada

\begin{tabular}{|c|c|c|c|c|}
\hline \multirow[b]{2}{*}{ No. } & \multirow[b]{2}{*}{ Pernyataan } & \multicolumn{2}{|c|}{ Analisis Skoring } & \multirow[b]{2}{*}{ Kriteria } \\
\hline & & $\begin{array}{l}\text { Jumlah } \\
\text { Skoring }\end{array}$ & $\begin{array}{c}\text { Indeks } \\
(\%)\end{array}$ & \\
\hline 1. & Pembagian sisa hasil usaha (SHU) tepat waktu & 165 & 7,67 & \\
\hline 2. & $\begin{array}{l}\text { Pembagian SHU ditempat yang sama setiap } \\
\text { bulannya }\end{array}$ & 177 & 8,23 & \\
\hline 3. & $\begin{array}{l}\text { Potongan dari SHU memiliki tujuan yang jelas } \\
\text { dan tidak memberatkan petani plasma kelapa } \\
\text { sawit }\end{array}$ & 177 & 8,23 & \\
\hline 4. & $\begin{array}{l}\text { Ada pembukuan yang jelas mengenai SHU yang } \\
\text { akan diperoleh petani plasma kelapa sawit atau } \\
\text { anggota KUD }\end{array}$ & 173 & 8,05 & \\
\hline 5. & $\begin{array}{l}\text { Perhitungan tonase Tandan Buah Segar (TBS) } \\
\text { diketahui oleh setiap pemilik lahan plasma kelapa } \\
\text { sawit sebagai anggota KUD }\end{array}$ & 160 & 7,44 & \\
\hline 6. & $\begin{array}{l}\text { Besar potongan SHU tak berubah-ubah setiap } \\
\text { tahunnya }\end{array}$ & 159 & 7,39 & \\
\hline 7. & $\begin{array}{l}\text { Besar potongan SHU yang diterima sama dengan } \\
\text { yang ada di pembukuan setelah dikurangi dengan } \\
\text { potongan }\end{array}$ & 176 & 8,19 & \\
\hline & $\begin{array}{l}\text { Dengan adanya KUD Karya Tani mampu } \\
\text { mengurangi pengangguran di desa Pandu Sanjaya }\end{array}$ & 184 & 8,55 & \\
\hline 9. & Setuju dengan adanya SHU & 178 & 8,28 & \\
\hline 10. & Jumlah SHU yang diterima setiap anggota sama & 170 & 7,91 & \\
\hline
\end{tabular}


besarnya dengan yang diterima oleh anggota KUD yang lain

Total

Sumber: Data Primer yang Diolah, 2019.

Pada Tabel 3, menunjukkan bahwa hasil analisis terhadap 43 responden petani plasma kelapa sawit, sikap petani plasma kelapa sawit terhadap kinerja pelayanan pembagian SHU pada KUD Karya Tani di Desa Pandu Sanjaya, Kecamatan Pangkalan Lada memiliki total skor sebanyak 1,846 (79,94\%) dimana termasuk dalam kriteria "Baik". Koperasi Unit Desa (KUD) Karya Tani memiliki keuangan yang dikelola terperinci dengan sangat baik dan terbuka untuk setiap anggota plasma kelapa sawit. Koperasi Unit Desa (KUD) Karya Tani juga meberikan besaran SHU yang dibagikan secara merata kepada para petani plasma kelapa sawit dalam pembagian SHU agar tidak terjadi kendala dan masalah yang dirasakan oleh petani plasma kelapa sawit.
Sikap Petani Plasma Kelapa Sawit Terhadap Kinerja Rapat anggota Tahunan dan Iuran Pada KUD Karya Tani di Desa Pandu Sanjaya Kecamatan Pangkalan Lada

Untuk mengetahui sikap petani plasma kelapa sawit terhadap kinerja rapat anggota tahunan dan iuran pada KUD Karya Tani di Desa Pangkalan Lada, Kecamatan Pangkalan Lada yaitu menggunakan kuesioner yang disajikan kepada responden. Adapun Tabel 4 memperlihatkan sikap petani plasma kelapa sawit terhadap kinerja rapat anggota tahunan dan iuran pada KUD Karya Tani di Desa Pandu Sanjaya, Kecamatan Pangkalan Lada.

Tabel 4. Penilaian Sikap Petani Plasma Kelapa Sawit Terhadap Kegiatan Kinerja Rapat anggota Tahunan dan Iuran pada KUD Karya Tani di Desa Pandu Sanjaya, Kecamatan Pangkalan Lada

\begin{tabular}{|c|c|c|c|c|}
\hline \multirow[b]{2}{*}{ No. } & \multirow[b]{2}{*}{ Pernyataan } & \multicolumn{2}{|c|}{ Analisis Skoring } & \multirow[b]{2}{*}{ Kriteria } \\
\hline & & $\begin{array}{l}\text { Jumlah } \\
\text { Skoring }\end{array}$ & $\begin{array}{l}\text { Indeks } \\
(\%)\end{array}$ & \\
\hline 1. & $\begin{array}{l}\text { Anggota mengikuti secara rutin Rapat Anggota } \\
\text { Tahunan (RAT) }\end{array}$ & 155 & 7,20 & \\
\hline 2. & $\begin{array}{l}\text { Memberikan saran-saran dalam Rapat Anggota } \\
\text { Tahunan (RAT) }\end{array}$ & 149 & 6,93 & \\
\hline 3. & $\begin{array}{l}\text { Memberikan masukan dalam Rapat Anggota } \\
\text { Tahunan (RAT) }\end{array}$ & 148 & 6,88 & \\
\hline 4. & $\begin{array}{l}\text { Anggota menggunakan hak suaranya dalam setiap } \\
\text { pengambilan keputusan dalam rapat }\end{array}$ & 151 & 7,02 & \\
\hline 5. & $\begin{array}{l}\text { Anggota memberikan saran saat rapat dalam } \\
\text { penempatan rencana kerja KUD }\end{array}$ & 143 & 6,65 & \\
\hline 6. & Anggota mebayar iuran pada KUD & 179 & 8,32 & \\
\hline 7. & $\begin{array}{l}\text { Jumlah besaran iuran yang dibayar oleh anggota } \\
\text { ditentukan oleh KUD }\end{array}$ & 139 & 6,46 & \\
\hline 8. & $\begin{array}{l}\text { Dana hasil iuran mimiliki kejelasan } \\
\text { penggunaannya dan tidak memberatkan anggota } \\
\text { KUD }\end{array}$ & 159 & 7,39 & \\
\hline 9. & $\begin{array}{l}\text { Anggota setuju dengan adanya iuan setiap } \\
\text { tahunnya }\end{array}$ & 165 & 7,67 & \\
\hline
\end{tabular}




\begin{tabular}{lllccc}
\hline 10. KUD memberikan kejelasan tentang laporan & 183 & 8,51 & \\
$\begin{array}{l}\text { keuangan setiap tahunnya kepada anggota plasma } \\
\text { kelapa sawit }\end{array}$ & & & \\
\hline & Total & 1.571 & 73,03 & Baik \\
\hline
\end{tabular}

Sumber: Data Primer yang diolah, 2019.

Berdasarkan pada Tabel 4, menunjukkan bahwa hasil analisis dari 43 responden petani plasma kelapa sawit, sikap petani plasma kelapa sawit terhadap kinerja rapat anggota tahunan dan iuran pada KUD Karya Tani di Desa Pandu Sanjaya, Kecamatan Pangkalan Lada memiliki total skor sebanyak 1,571 $(73,03 \%)$, dimana termasuk dalam kriteria "Baik". Koperasi Unit Desa (KUD) Karya Tani selain melakukan Rapat Anggota Tahunan (RAT) yang dilakukan setiap satu tahun sekali yaitu pada saat tutup buku, petugas KUD Karya Tani dan anggota petani plasma bersama-sama melakukan iuran wajib sukarela yang dilakukan setiap tutup buku bersamaan dengan Rapat Anggota Tahunan (RAT). Kehadiran anggota KUD Karya Tani dan petani plasma kelapa sawit dalam mengikuti rapat anggota tahunan sangat baik hal ini dapat dilihat dari pernyataan yang disampaikan oleh ketua, anggota, dan pengurus KUD Karya Tani. Dengan kehadiran para petani plasma dalam rapat anggota tahunan diharapkan petani plasma memberikan ide, kritik, saran, dan pendapat agar kedepannya KUD Karya tani menjadi lebih baik lagi dari tahun ke tahunnya. Rapat anggota tahunan dan iuran yang diadakan oleh KUD Karya Tani yaitu setiap satu tahun sekali pada saat tutup buku.

\section{Sikap Petani Plasma Kelapa Sawit Terhadap Kinerja Pelayanan pada KUD Karya Tani di Desa Pandu Sanjaya, Kecamatan Pangkalan Lada}

Untuk mengetahui sikap petani plasma kelapa sawit terhadap kinerja pelayanan pada KUD Karya Tani di Desa Pandu Sanjaya, Kecamatan Pangkalan Lada menggunakan 4 varibel indikator dengan jumlah pernyataan sebanyak 36 yang diajukan kepada 43 responden petani plasma yang bermukim di Desa Pandu Sanjaya, Kecamatan Pangkalan Lada, dapat dilihat pada Tabel 5 berikut.

Tabel 5. Penilaian Sikap Petani Plasma Kelapa Sawit Terhadap Kinerja Pelayanan pada KUD Karya Tani di Desa Pandu Sanjaya, Kecamatan Pangkalan Lada, Kabupaten Kotawaringin Barat

\begin{tabular}{|c|c|c|c|c|c|}
\hline \multirow[b]{2}{*}{ No. } & \multirow[b]{2}{*}{ Pernyataan } & \multicolumn{2}{|c|}{ Analisis Skoring } & \multirow[b]{2}{*}{ Indeks } & \multirow[b]{2}{*}{ Kriteria } \\
\hline & & $\begin{array}{c}\text { Total } \\
\text { Skoring }\end{array}$ & $\begin{array}{c}\text { Indeks } \\
(\%)\end{array}$ & & \\
\hline 1. & $\begin{array}{l}\text { Penilaian Sikap Petani Plasma Kelapa } \\
\text { Sawit Terhadap Kinerja Pelayanan } \\
\text { Pinjaman Pada KUD Karya Tani di } \\
\text { Desa Pandu Sanjaya Kecamatan } \\
\text { Pangkalan Lada }\end{array}$ & 1.563 & 72,68 & 20,19 & \\
\hline 2. & $\begin{array}{l}\text { Penilaian Sikap Petani Plasma Kelapa } \\
\text { Sawit Terhadap Kinerja Pelayanan } \\
\text { Penyediaan Pupuk Pada KUD Karya } \\
\text { Tani di Desa Pandu Sanjaya } \\
\text { Kecamatan Pangkalan Lada }\end{array}$ & 1.060 & 79,05 & 13,69 & \\
\hline
\end{tabular}




$\begin{array}{lllll}\text { 3. Penilaian Sikap Petani Plasma Kelapa } & 1.846 & 79,94 & 23,85 \\ \text { Sawit Terhadap Kinerja Pelayanan } & & & \\ \text { Pembagian SHU Pada KUD Karya } & & & \\ \text { Tani di Desa Pandu Sanjaya } & & & \\ \text { Kecamatan Pangkalan Lada } & & & \\ \text { 4. Penilaian Sikap Petani Plasma Kelapa } 1.571 & 73,03 & 20,30 \\ \text { Sawit Terhadap Kegiatan Kinerja } & & & \\ \text { Rapat Anggota Tahunan (RAT) dan } & & & \\ \text { Iuran Pada KUD Karya Tani di Desa } & & & \\ \text { Pandu Sanjaya Kecamatan Pangkalan } & \end{array}$

\begin{tabular}{cccc}
\hline Total & 6.040 & 78,03 & Baik \\
\hline
\end{tabular}

Sumber: Data Primer yang Diolah, 2019.

Berdasapkan Tabel 5, diketahui bahwa sikap petani plasma kelapa sawit terhadap kinerja pelayanan pada KUD Karya Tani di Desa Pandu Sanjaya, Kecamatan Pangkalan Lada, Kabupaten Kotawaringin Barat tergolong dalam kriteria "BAIK". Penentuan sikap terhadap 4 indikator variabel diantaranya adalah: 1). Penilaian sikap petani plasma kelapa sawit terhadap kinerja pelayanan pinjaman pada KUD Karya Tani di Desa Pandu Sanjaya, Kecamatan Pangkalan Lada dengan indeks 72,68\% termasuk dalam kriteria "BAIK"; 2). Penilaian sikap petani plasma kelapa sawit terhadap kinerja pelayanan penyediaan pupuk pada KUD Karya Tani di Desa Pandu Sanjaya, Kecamatan Pangkalan Lada dengan indeks 79,05\% termasuk dalam kriteria "BAIK"; 3). Penilaian sikap petani plasma kelapa sawit terhadap kinerja pelayanan pembagian SHU pada KUD Karya Tani di Desa Pandu Sanjaya, Kecamatan Pangkalan Lada dengan indeks 79,94\% termasuk dalam kriteria "BAIK"; 4). Penilaian sikap petani plasma kelapa sawit terhadap kegiatan kinerja RAT dan iuran pada KUD Karya Tani di Desa Pandu Sanjaya, Kecamatan Pangkalan Lada dengan indeks 73,03\% termasuk dalam kriteria "BAIK". Berdasarkan 4 indikator variabel tersebut maka sikap petani plasma kelapa sawit terhadap kinerja pelayanan pada KUD Karya Tani memperoleh indeks 78,03\% dengan kriteria "BAIK", yang berarti pula sikap pelayanan KUD Karya Tani sudah berkinerja baik dalam menjalankan program-program kerjanya.

Permasalahan yang Dihadapi oleh Petani Plasma Kelapa Sawit Terhadap Kinerja Pelayanan pada KUD Karya Tani di Desa Pandu Sanjaya, Kecamatan Pangkalan Lada, Kabupaten Kotawaringin Barat

Sikap petani plasma kelapa sawit terhadap kinerja pelayanan simpan pinjam, pelayanan penyedia pupuk, pembagian SHU, RAT dan iuran pada KUD Karya Tani di Desa Pandu Senjaya, Kecamatan Pangkalan Lada termasuk dalam kriteria "BAIK". Namun dari kriteria "BAIK" tersebut ada beberapa permasalahan yang dirasakan oleh beberapa anggota petani plasma kelapa sawit diantaranya yaitu: 1). Keterbatasan pelayanan penyedia pupuk bersubsidi. Terbatasnya ketersediaan pupuk yang ada di KUD Karya Tani membuat beberapa dari anggota petani harus mencari tambahan pupuk diluar dari KUD. Seperti jumlah pupuk yang disediakan berdasarkan jenis pupuk terbatas, jenis pupuk yang disediakan tidak sesuai dengan kebutuhan petani plasma. Pihak KUD Karya Tani hanya menjual pupuk jenis Urea, $\mathrm{KCl}$, TSP, dan NPK dengan kualitan baik, sedangkan yang dibutuhkan petani plasma tidak hanya pupuk jenis itu saja. Anggota petani plasma berharap agar KUD Karya Tani 
bisa menyediakan beberapa jenis pupuk lain seperti pupuk Dolomit, SP-36 dan Borak yang berfungsi untuk membantu mempercepat tanaman kelapa sawit dalam menyerap unsur hara, merangsang pertumbuhan buah dan mempercepat buah matang. Petani plasma merasa bahwa pupuk yang dijual dipasaran harga pupuk tergolong cukup mahal dibandingkan dengan harga jual yang diberikan oleh KUD Karya Tani. Harapan ini sudah disampaikan oleh anggota petani plasma kelapa sawit dari beberapa tahun terakhir melalui RAT namun hingga saat ini belum juga terpenuhi; 2). Masalah lain yaitu keterbatasan dalam hal pelayanan simpan pinjam, meskipun pelayanan simpan pinjam masuk dalam kriteria "BAIK" namun di sisi lain ada beberapa anggota yang mempermasalahkan pelayanan simpan pinjam. Seperti dalam segi pinjaman modal meskipun sudah ditentukan bersama antara pengurus KUD Karya Tani dengan anggota petani plasma kelapa sawit dan sudah mencapai kesepakatan bersama dengan besaran pinjaman sebesar Rp 30.000.000 dengan jangka waktu pinjaman selama 36 bulan dengan bunga pinjaman tetap sebesar $1,5 \%$ dan sudah berjalan lama. Namun ada beberapa anggota yang mengeluh dan merasa bahwa pinjaman yang diberikan oleh KUD Karya Tani terlalu sedikit tidak cukup untuk memenuhi kebutuhan anggota petani plasma, sehingga menyebabkan petani harus meminjam di tempat lain. Beberapa anggota petani plasma berharap agar KUD Karya Tani bisa memberikan jumlah pinjaman yang sesuai dengan kebutuhan petani plasma kelapa sawit. Namun harapan tersebut tidak dipenuhi oleh pengurus KUD Karya Tani dikarenakan sudah kesepakatan bersama, dan tabungan KUD Karya Tani yang diperoleh dari investasi dan simpanan anggota terbatas. Bila dari segi pelayanannya sudah sangat baik. Adapun 2 pelayanan KUD Karya Tani yang dirasa anggota petani bagus dan tidak ada masalah yaitu pembagian SHU, RAT dan Iuran karena apa yang dibutuhkan oleh anggota petani plasma kelapa sawit sudah tercukupi dengan baik.

\section{KESIMPULAN DAN SARAN}

\section{Kesimpulan}

Berdasarkan hasil dan pembahasan, maka dapat disimpulkan sebagai berikut:

1. Sikap petani plasma kelapa sawit terhadap kinerja pelayanan dan kegiatan pada KUD Karya Tani di Desa Pandu Sanjaya, Kecamatan Pangkalan Lada, Kabupaten Kotawaringin Barat berkriteria "BAIK", yang berarti pula sikap pelayanan KUD Karya Tani sudah berkinerja baik dalam menjalankan program-program kerjanya.

2. Permasalahan yang dirasakan oleh beberapa anggota petani plasma kelapa sawit yaitu: 1). Keterbatasan pelayanan penyediaan pupuk bersubsidi; 2). Keterbatasan dalam pelayanan simpan pinjam.

\section{Saran}

Berdasarkan kesimpulan, maka disarankan sebagai berikut:

1. Diharapkan KUD Karya Tani bisa memenuhi harapan anggota petani plasma kelapa sawit terutama dari segi penyediaan jumlah pupuk bersubsidi yang sama dan jenis pupuk bersubsidi yang sesuai dengan permintaan. Selanjutnya untuk pelayanan pinjaman modal diharapkan KUD Karya Tani bisa memberikan jumlah pinjaman yang sesuai dengan kebutuhan sesuai Anggaran Rumah Tangga petani plasma kelapa sawit. Koperasi Unit Desa (KUD) Karya Tani diharapkan lebih meningkatkan investasi dan simpanan anggota agar bisa mencukupi kebutuhan KUD Karya Tani dan anggota petani plasma kelapa sawit. 
Kepada Petani plasma diharapkan selalu membayar angsuran dengan tepat waktu agar dana yang masuk bisa berkembang kembali, dengan demikian bisa membantu KUD Karya Tani semakin maju.

2. Melalui Pemerintah Daerah khusunya Dinas Koperasi, Usaha Kecil dan Menengah (UKM) Kabupaten Kotawaringin Barat agar lebih memperhatikan KUD Karya Tani mengingat KUD Karya Tani ini merupakan KUD yang paling maju dan sudah memiliki banyak prestasi dibidang pengembangan plasma kelapa sawit.

\section{DAFTAR PUSTAKA}

Arikunto, Suharsimin. (2010). Prosedur Penelitian. Jakarta: Rhineka Cipta.

Badan Pusat Statistik Kabupaten Kotawaringin Barat. (2018). Kotawaringin Barat Dalam Angka 2017. Pangkalan Bun: Badan Pusat Statistik Kabupaten Kotawaringin Barat.

Badan Pusat Statistik Provinsi Kalimantan Tengah. (2018). Kalimantan Tengah Dalam Angka 2017. Palangka Raya: Badan Pusat Statistik Provinsi Kalimantan Tengah.

Bahroni, Ahmad. (2018). Analisis Pendapatan dan Tingkat Kesejahteraan Rumah Tangga Petani Plasma Kelapa Sawit di Desa Pandu Sanjaya, Kecamatan Pangkalan Lada, Kabupaten Kotawaringin Barat. Skripsi. Program Studi Agribisnis. Fakultas Pertanian. Universitas Palangka Raya.

Darmawan, Baskoro W. (2010). Sikap Petani Terhadap Pengembangan Usaha Agribisnis Pedesaan (PUAP) di Kota Salatiga. Skripsi. Program Studi Agribisnis. Fakultas
Pertanian. Universitas Sebelas Maret Surakarta.

Dinas Koperasi dan UKM Provinsi Kalimantan Tengah. (2018). Keragaman Koperasi Unit Desa di Kecamatan Pangkalan Lada, Kabupaten Kotawaringin Barat 2017. Palangka Raya: Dinas Koperasi dan UKM Provinsi Kalimantan Tengah.

Wardie, J. dan Taufik, E. N. (2017). Kajian Implementasi Program Perusahaan Perkebunan Kelapa Sawit Kepada Masyarakat di Kabupaten Kotawaringin Barat. http://ejournal2.undip.ac.id/index.p hp/agrisocionomic/2017/05.

Diakses pada tanggal 17 Februari 2020.

Sapto, S. W. (2016). Sikap Petani Plasma Kelapa Sawit Terhadap Pelayanan Koperasi Unit Desa (KUD) Karya Tani di Desa Mekar Jaya, Kecamatan Parenggean, Kabupaten Kotawaringin Timur. Skripsi. Program Studi Agribisnis. Fakultas Pertanian, Universitas Palangka Raya.

Sugiyono. (2017). Metode Penelitian Kuantitatif, Kualitatif, dan R \& D. Bandung: Alfabeta.

Silitonga, Y. R. (2017). Sikap Petani Terhadap Program Pengembangan Usaha Agribisnis Pedesaan Lokasi Trans 38 Tangkiling Kelurahan Sei Gohong Kota Palangka Raya. Skripsi. Fakultas Pertanian. Universitas Palangka Raya.

Zakaria, W. A. (2008). Penguatan Kelembagaan Kelompok Tani Kunci Sukses Kesejahteraan Petani. Bogor: Pusat Analisis Sosial Ekonomi dan Kebijakan Pertanian. 